\title{
Desafios da Qualidade e Produtividade à Engenharia de Produção do Brasil
}

\author{
Lin Chih Cheng \\ João Martins da Silva \\ Francisco de Paula A. Lima
}

Departamento de Engenharia de Produção
Escola de Engenharia da Universidade Federal de Minas Gerais
Rua Espirito Santo, $35-7^{\circ}$ andar - Centro
30160-030 - Belo Horizonte - MG

Palavras-chave: Avaliação, Desafios, Qualidade, Produtividade, Engenharia de Produção.

Key-words: Evaluation, Quality, Productivity, Production Engineering, Prospects Limitations.

\section{RESUMO}

Este trabalho faz uma avaliação histórica e do estágio atual do movimento qualidade e produtividade (Q\&P) no Brasil, através da evolução do conceito do controle da qualidade no interior do atual processo de reestruturação produtiva, $e$ delineia os desafios, limitações e potencialidades desse movimento à comunidade científica da Engenharia de Produção. $O$ escopo da análise está centrado, principalmente, na comparação entre a prática da Q\&P do setor produtivo industrial brasileiro com o corpo conceitual-teórico da Q\&P conhecido pela comunidade. O argumento central do trabalho é "Q\&P (no seu sentido amplo, incluindo o trabalho) não pode ser visto como uma sub-área da Engenharia de Produção, mas sim a própria razão de ser da Engenharia de Produção (no seu sentido igualmente amplo, incluindo o trabalho)". Duas idéias decorrentes desse argumento principal são: 1- a demanda por Q\&P abre espaço para a utilização do conhecimento especializado da Engenharia de Produção; 2 - os pressupostos básicos de Q\&P abrem horizonte para a formulação de uma nova base teórica e prática da Engenharia de Produção. O trabalho conclui com a descrição de um conjunto de ações que podem ser implementadas pelos pesquisadores, associações afins e órgãos de fomento para que esta área de conhecimento possa ser mais amplamente aplicada em beneficio da sociedade brasileira.

\section{ABSTRACT}

This paper sets out to provide a historical review and an evaluation of the current situation of the $Q$ uality and Productivity ( $Q \& P$ ) efforts in Brazil through the evolution of the concept of quality control within the framework of the current process of changes in the production system. This paper also outlines the challenges, future prospects and limitations that these efforts offer to professionals of Production Engineering. The scope of this analysis is mainly based on the comparison between the practice of $Q \& P$ within Brazilian industry and the theoretical concept of $Q \& P$ as understood by those professionals. The main assumption in this paper is that " $Q \& P$ (in its wider meaning) should not be viewed as part of Production Engineering, but it is the raison d'etre of Production Engineering (in an equally wider meaning). Two main ideas stem from this assumption, which are: (1) the demand for $Q \& P$ provides ample room for the application of the specialized knowledge in Production Engineering and (2) the fundamental assumptions of $Q \& P$ enable the formulation of a new theoretical and practical framework for Production Engineering. Finally, this paper describes a set of actions which can be implemented by researchers, associations of professionals and foster-organizations so that this field of knowledge can be put in practice more widely for the benefit of the whole Brazilian society. 


\section{Introdução}

Este trabalho originou-se da solicitação da Comissão Organizadora do XIV ENEGEP para elaborar um material na área de Q\&P que pudesse subsidiar os debates que se seguiram ao encontro, e que, ao final, pudesse integrar o documento "Avaliação e Perspectivas" (Lustosa \& Iida, 1989) nos moldes do Conselho Nacional de Desenvolvimento Científico e Tecnológico (CNPq), auxiliando a potencializar e orientar os esforços da área junto à comunidade acadêmica, associações afins e instituições de fomento.

O grupo temático Q\&P da Engenharia de Produção aparece formalmente no IX ENEGEP (em Porto Alegre - 1989) com o tema Qualidade e Confiabilidade, com a apresentação de 8 trabalhos (Anais do IX ENEGEP, 1989). Anteriormente, no VIII Encontro (em São Carlos - 1988), apesar de ter tido 8 grupos temáticos, Q\&P ainda não aparecia como um tema que merecesse uma discussão à parte (Anais do VIII ENEGEP, 1988). No X ENEGEP (em Belo Horizonte - 1990), Q\&P apresentava-se amalgamado à Engenharia do Produto, sob o tema de "Engenharia de Produto \& Qualidade e Confiabilidade" (Anais do X ENEGEP, 1990). No último encontro - XIII ENEGEP (em Florianópolis - 1993) o grupo temático "Gestão da Qualidade e Produtividade" figura entre os 8 grupos como o tema que apresentou mais trabalhos - 66 num total de 209 (Anais do XIII ENEGEP, 1993). O aspecto mais interessante foi a postura inédita da Comissão Técnica do evento, que colocou o tradicional tema de Gerência da Produção sob o tema Q\&P.

A partir dessas constatações, duas conclusões podem ser tiradas. A primeira é o número crescente de trabalhos, e como inferência direta, maior número de pessoas da comuni- dade de Engenharia de Produção com interesse nesse tema. A segunda conclusão é com relação à divisão dos grupos temáticos. Percebe-se que os organizadores dos ENEGEPs não possuem uniformidade de critério na formação dos temas dos sub-grupos, particularmente com relação ao tema Q\&P. Constata-se que $\mathrm{Q} \& \mathrm{P}$, ora não é contemplado, ora é visto como um grupo temático à parte, ora está junto com Engenharia do Produto e, finalmente, até engloba o grupo temático mais tradicional de Gerência da Produção. Pode-se dizer, portanto, que apesar da relevância e do crescente interesse por esse tema, não há uma compreensão precisa do que é Q\&P. Pretende-se, através desse trabalho, prestar auxílio à compreensão do tema e avançar o argumento de que $Q \& P$, no seu sentido mais amplo, não pode ser tratado como uma sub-área da Engenharia de Produção (EP), mas sim como a própria razão de ser da EP. Com efeito, Q\&P, na sua forma abrangente atual, por um lado enfatiza a presença e a participação dos trabalhadores no processo produtivo e se preocupa com a qualidade de vida no trabalho e por outro, se ocupa não apenas da clássica função de controle da qualidade, mas da globalidade do processo de produção voltado para a qualidade. Assim, não é de se estranhar que uma e outra acabem por se confundir, dada a abrangência que hoje assume Q\&P.

A estrutura do trabalho está dividida em três partes. A primeira parte descreve o processo de evolução do tema Q\&P. Na segunda parte uma análise é feita, destacando as limitações e potencialidades. E, finalmente, um conjunto de ações é proposto para ser implementado.

\section{Evolução da Q \& P}

Épossivel identificar pelo menos dois com- 
plexos conjuntos de fenômenos que têm influenciado a evolução do Q\&P.O primeiro deles diz respeito à competição das nações e blocos de nações que disputam as fatias de mercado a nível global, através de setores industriais específicos (Porter, 1989, 1993; Thurow, 1992). O que cada país tem procurado é a sua inserção no mundo dos países considerados desenvolvidos, procurando formas mais vantajosas de se situar na nova dinâmica econômica global. Para que isso aconteça tem-se exigido das nações o empenho e a implementação de programas nacionais de Q\&P (PBQP, 1991). Apesar da extrema importância desses processos macroeconômicos em escala mundial, nos limitaremos aqui a mencioná-los o suficiente para situar nosso problema. $O$ segundo aspecto está relacionado com as mudanças da própria concepção de Controle da Qualidade (e os conceitos necessários para se reorganizar a produção, em consequência), que acompanham essas mudanças mais gerais.

\section{Tendências Macroeconômicas e Q\&P}

Q\&P se nos apresenta hoje como um conjunto multiforme de princípios, conceitos, técnicas e ferramentas organizacionais e administrativas (Qualidade Total, ISO 9000, Reengenharia, etc.), alguns novos, outros herdados de teorias e práticas anteriores (taylorismo, Escola de Relações Humanas, instrumentos da engenharia de produção, etc...), que são arrolados de forma sistemática, cuja articulação se faz em torno e graças à "qualidade". Sem nenhuma dúvida, a "Gerência da Qualidade Total" (QT) é, no Brasil de hoje, a teoria organizacional que detém a hegemonia no plano das ideologias e práticas gerenciais. Antes de avaliarmos, em detalhe, sua situação atual e perspectivas, vejamos o que constitui a QT e como ela se constituiu no Brasil.

Dois aspectos a se destacar nesta definição preliminar: o seu caráter "multiforme" e o papel central da categoria "qualidade". Ambos refletem o processo histórico geral de constituição da teoria (cuja cor característica provém do Japão), e tendem a se repetir em sua introdução no Brasil.

No Japão, após um rápido florescimento da produção industrial no pós-guerra, sentiuse fortemente a necessidade de melhorar a qualidade dos produtos para alcançar competitividade no mercado externo, dominado por países e empresas com uma longa tradição. Para resolver esse problema prático, todas as teorias técnicas eram bem-vindas, algumas das quais não encontravam aceitação no país de origem (o caso de Deming é exemplar). Por outro lado, pressionado pelas condições internas adversas (recursos geográficos, financeiros, materiais e equipamentos escassos), procuraram desenvolver formas de organização da produção mais apropriadas (notadamente a troca rápida de ferramentas e o JTT-KANBAN. Tudo isso se deu num contexto sociopolítico, (tradição, sindicato por empresa, posição da mulher na familia, etc) que propiciou a emergência de formas de organização do trabalho e de implicação dos trabalhadores japoneses nos valores e metas das empresas. Independentemente dos processos reais de aparecimento desses diferentes elementos e de seu peso efetivo na reorganização industrial do Japão, o fato é que eles caracterizam uma forma de produzir, cuja natureza ainda está em debate (Coriat, 1991; Lima, 1993; Hirata, 1993), que contribuiu parà o surgimento do Japão como potência econômica. Daí o seu forte poder de atração para países do "Terceiro Mundo", como o Brasil, que se encontram diante da necessidade imperiosa de se integrar à economia mundial e, sobretudo, fazê-lo em 
condições de guardar sua soberania interna, $\mathrm{e}$ não apenas ser "fagocitado" pelo processo de globalização da economia.

A penetração do ideário da QT no Brasil deu-se, então, diferentemente do Japão, num quadro econômico bem mais desfavorável no plano interno (recessão, base industrial e mercado interno não plenamente desenvolvidos) e no externo (competição acirrada, mudança do patamar tecnológico). Retornaremos a esta situação na avaliação das perspectivas; por enquanto, importa assinalar que a QT já conquistou a hegemonia dentre as ideologias gerenciais, e analisar como isso se deu.

O pano de fundo, como vimos, é uma situação de competitividade acirrada mundialmente, potencializada pela relativa abertura dos mercados internos, e pelo fim do protecionismo exagerado do Estado, que havia criado uma espécie de "capitalismo cartorial". As empresas, nestas condições, devem forçosamente adaptar-se, procurando novos padrões de competitividade.

A QT aparece, então, como a teoria organizacional-administrativa que melhor atenderia a essas necessidades. Traduzida em forma de princípios e técnicas gerenciais, a experiência Japonesa foi importada no bojo do Programa Brasileiro de Qualidade e Produtividade (PBQP). Hoje, é possivel assegurar que a QT já foi incorporada ao cotidiano das empresas. Outros indícios, se necessário fosse, ainda reforçam esta afirmação: alto interesse dos alunos de graduação de várias áreas em conhecê-la e a divulgação de fascículos sobre $o$ assunto num jornal de grande circulação nacional. Vejamos como essas tendências econômicas se refletem na esfera da produção e nos conceitos de controle de qualidade, isto é, nos objetos da EP propriamente dita.

\section{Mudança das Concepções e dos Conceitos do Controle da Qualidade}

Paralelamente a essas tranformações macroeconômicas globais, cuja dinâmica e efeitos são ainda pouco conhecidos, aparecem novas concepções de organização e gestão da produção. É nesse plano que a EP se vê confrontada a novos critérios e formas de organização da produção, dentre as quais o que comumente se denomina de "controle da qualidade". A prática do controle da qualidade tem sido feita, históricamente, de três modos distintos: via inspeção, via controle de processo, desde o desenvolvimento do produto. $\mathrm{O}$ primeiro modo é caracterizado pela separação do defeituoso do perfeito, comparando o produzido contra um padrão. $O$ segundo modo caracteriza-se pelo controle de todos os processos envolvidos na formação do produto final, tanto no seu efeito como nas suas causas. O controle é centrado no "como" da formação do produto final, e não na detecção quando o produto já está formado. $O$ terceiro modo é a prática do controle da qualidade desde o desenvolvimento do produto. Se no primeiro modo visa-se detectar algo errado do produto final já pronto, e no segundo modo visa-se formar bem o que foi especificado, o terceiro modo vai além, e visa conceber bem o que se propõe a formar. Estes três modos podem ser vistos como uma evolução do processo de controle da qualidade, e esta evolução é a operacionalização do conceito de "controle à montante" no ciclo de vida do produto dentro de uma empresa. É importante, ainda, salientar que os modos de prática do controle da qualidade não são mutuamente excludentes, mas sim, na realidade, elas muitas vezes são praticadas de forma complementar. Portanto, pode-se dizer que a distinção está na ênfase e não na exclusão de uma forma em relação a outra, na prática do controle da qualidade. 
A idéia do controle da qualidade pelo controle do processo iniciou-se na década de 1930 com Shewhart e Deming nos Estados Unidos, e por volta de 1949 no Japão (Ishikawa, 1984). Desde então, essa prática é usual nas empresas japonesas. Quanto à idéia da garantia da qualidade pelo controle da qualidade desde o desenvolvimento do produto, esta apareceu porvolta de 1959, quando ainda se praticava garantia da qualidade via inspeção e controle do processo (Ishikawa, 1984). Sabia-se, desde então, que, para que as empresas fossem verdadeiramente competitivas, não bastava "fazer ou formar bem", mas precisava-se ir além dessa prática, i.e., precisava-se "conceber e projetar bem" os produtos. Entretanto, a operacionalização da idéia ou a colocacão em prática da idéia de controle da qualidade desde o desenvolvimento do produto, através do método de Desdobramento da Função Qualidade (QFD) (Akao, 1972, 1990), parece ter tido um lapso de mais ou menos uma década. Evidentemente trata-se, sobretudo, da sistematização e operacionalização de tendências já manifestas, tanto na área de projeto do produto quanto na EP propriamente dita. O que deve ser ressaltado é que, no Japão, essas idéias, freqüenternente restritas ao mundo acadêmico, foram amplamente utilizadas, trazendo profundas consequências para a própria concepção de organização da produção da empresa, e mesmo de setores industriais inteiros.

A prática do controle da qualidade em empresas brasileiras, de uma maneira geral, pode-se dizer que se concentra nos dois primeiros modos, com raras exceções já enfatizando o terceiro modo (FCO, 1992, 1993). É possível fazer esta afirmação com certa precisão baseado, principalmente, no trabalho da Fundação Christiano Ottoni, da Escola de Engenharia da UFMG. O trabalho desta, em termos de ênfase e escopo, concentra-se na segunda forma do controle da qualidade. Reforçando esta constatação, verifica-se que na indústria automobilistica há também esta ênfase, pois em recentes processos de auditoria das montadoras sobre as fornecedoras de autopeças, ainda está sendo exigido a confecção e o uso de planos de controle da qualidade dos processos, como a prática do controle da qualidade (GM do Brasil, 1991). Quanto ao avanço para o terceiro modo de controle da qualidade, existe, sim, uma incipiência, pois o uso do método QFD como um "orientador do projeto e processo do produto", tem sido recomendado, explicitamente, por apenas uma montadora aos seus fornecedores (GM do Brasil, 1991). Entretanto, sabe-se que as empresas fornecedoras de autopeças não possuem uma forte tradicão em projetar os produtos que fabricam, pois até pouco tempo recebiam as especificações e desenhos já prontos das montadoras.

Nesta última concepção, controle da qualidade visa assegurar ou garantir a qualidade do produto e da empresa às pessoas de diversos segmentos - funcionários, acionistas, clientes, vizinhos e a sociedade como um todo. A garantia da qualidade definida como propósito é algo, acima de tudo, dinâmico, em vez de ser estático, e especifico, em vez de ser generalizável. Isto significa, num primeiro momento, que por causa da dinâmica das necessidades com o decorrer do tempo, há uma constante mudança no que é satisfatório para cada um dos segmentos. Num segundo momento, o que é satisfatório para um contexto específico com componentes intrínsecos, necessita de medidas autóctones, pois sem as devidas adaptações, o potencial das filosofias e métodos gerenciais fica limitado, e o contexto onde é aplicado é violentado. Daí a necessidade imperiosa de descentralizar o processo de concepção dos produtos, apostando na autonomia dos fornecedores para 
suprir as necessidades de seus clientes.

\section{Mudanças Decorrentes da Mudança do Conceito do Controle da Qualidade}

O que se pode concluir é que, com a evolução do conceito do controle da qualidade, é possivel identificar pelo menos duas mudanças importantes: visão do potencial do homem e escopo do controle da qualidade.

O pressuposto quanto ao potencial do homem, com a evolução do conceito da qualidade, passou a ser mais "voluntarista" - o ser humano possui uma maior capacidade de ser o agente transformador do ambiente que o cerca no lugar de ser um mero influenciado pelo ambiente, um produto do ambiente sem capacidade de transformá-lo. (Burrel \& Morgan, 1979) Por exemplo, para o grande contingente de homens, anteriormente restrito ao nivel de execução, vê-se que eles são mais do que capazes de planejar, verificar o próprio trabalho, e efetuar ação corretiva. Eles são mais do que capazes de estabelecer as relações de causas-e-efeitos dos processos sob seus cuidados, e em aperfeiçoar os modos de execução das suas tarefas. Por outro lado, aqueles que no passado eram meros capatazes (inclusos os de formação nível superior), são agora considerados como capazes de aprofundar os seus conhecimentos, tanto no plano de gestão, como no plano da tecnologia intrínseca aos processos. Mantem-se a divisão do trabalho, mas com atribuição de novas funções aos escalóes inferiores, dando-lhes uma autonomia relativa.

A segunda mudança concerne o objeto visado pelo controle da qualidade, pois a tarefa controle da qualidade anteriormente executada pelo inspetor passa a ser controle de todos os processos produtivos, desde o planejamento de um produto até a assistência técnica do produto vendido, feito por todos, dentro de uma organização, direcionados para Q\&P. Isso significa que os temas tradicionais da Engenharia de Produção, como inovação tecnológica, desenvolvimento do produto, localização industrial e dos lay-outs, estratégias de produção, planejamento e controle da produção, organização do trabalho e técnicas de otimização, podem ser vistos, doravante, como áreas de estudo voltados para Q\&P. E, vice versa, a $Q \& P$ passa a depender da interação complexa de todas essas áreas comumente separadas na teoria e na prática produtivas.

Essas duas mudanças justificam o argumento central deste artigo - $Q \& P$ é a razão de ser da EP e não pode, portanto, ser visto como uma sub-área, ambas, evidentemente, entendidas no sentido amplo, como foi caracterizado neste artigo. Isso posto, resta-nos perguntar pelas tarefas atuais e perspectivas, o que exige uma análise mais crítica e não um simples relato descritivo, como feito até o momento.

\section{Análise: Potencialidades e Limitações da Q \& P}

\section{Potencialidades do Tema Q\&P}

Para muitos, a simplicidade dos conceitos e técnicas do tema Q\&P, até agora conhecidos e formalizados, representaria uma deficiência diante da realidade complexa e contraditória da produção. Entretanto, parece-nos que, de certo modo, esta simplicidade se tomou uma potencialidade, pois através dela o tema $\mathrm{Q} \& \mathrm{P}$ aparece como essencial para muitos. Por exemplo, os conceitos de "cliente" e de "fornecedor" - processos, respectivamente, 
posterior e anterior - são extremamente importantes. $O$ que se quer obter com esses conceitos é a estruturação dos postos de trabalho, setores de produção e empresas, através do espírito de cooperação entre os indivíduos, e parcerias entre empresas. O ciclo "PDCA" (Planejar, Executar, Verificar e Agir Corretivạmente) não é nada novo como método gerencial. Entretanto, os instrumentos de operacionalização por intermédio dos $5 \mathrm{Ws}$ e $1 \mathrm{H}$ e o relatório de três gerações (passado, presente e futuro) fazem com que o ciclo seja imediatamente visivel. Essa visibilidade gerencial é o cerne do uso do método. Com relação à ferramenta do diagrama de causa-eefeito, a finalidade do diagrama não é correlacionar causas e efeitos de forma hierárquica. Também aqui, o que se-quer é a visibilidade das relações entre as causas e os efeitos para que os que controlam os processos possam aprender um com o outro, e melhorar continuamente.

Pode-se verificar, então, que os conceitos, métodos e técnicas do Q\&P, mais conhecidas, são extremamente simples e de aplicação generalizada. Entretanto, para que o Q\&P continue a desenvolver, é necessário métodos e técnicas mais apuradas da Engenharia de Produção que, no caso do Japão, jả são ensinadas e utilizadas, há muitos anos, pela Union of Japanese Scientists and Engineers no interior do controle da qualidade (JUSE, 1991). Os métodos e técnicas de natureza mais simples servem para efetuar a "sintonia" grossa, enquanto aqueles, de natureza mais apurada, servem para efetuar a "sintonia" fina.

A segunda potencialidade do Q\&P é a estrutura ou o arcabouço conceitual já estabelecidos. Tanto a estratégia da qualidade segundo a Norma Série ISO 9000 , ou a estratégia Controle da Qualidade Total, estabelecem Sistemas de Garantia da Qualidade que englo- bam, de forma ordenada, todas as funções da empresa, para que um produto ou serviço possa satisfazer aos clientes. A ordenação que vai desde a pesquisa de mercado, passando pelas funções de projeto conceitual, intermediário e detalhado, fabricação do protótipo, projeto do processo, produção do lote piloto, preparação para produção em série, suprimento, sub-contratação, até vendas e assistência técnica, permite localizar, de forma clara, quais são os métodos e técnicas de otimização e estatisticas a serem utilizadas. A moldura estabelecida de fácil entendimento, e a listagem dos respectivos métodos e técnicas de fácil visualização, permitem uma compreensão total, potencializando o tema Q\&P (Drumond, 1994; JUSE, 1991).

A terceira potencialidade é a estratégia de pesquisa recomendada para o tema Q\&P. Estratégia de pesquisa pode ser entendida como o meio pelo qual uma metodologia é operacionalizada. É um conjunto de regras, conceitos e teorias que regem a interação entre o pesquisador e o fenômeno a ser estudado. A estratégia de pesquisa é a interrelação entre pressupostos paradigmáticos e imagens epistemológicas, e algumas dessas estratégias entre outras são: quase-experimentação, pesquisa ação, interacionismo simbólico, e método dialético para análise organizacional (Morgan, 1983). O pesquisador de Q\&P, ao interagir com o fenômeno, auxilia os membros do setor produtivo a resolverem os seus problemas práticos e, ao mesmo tempo, desenvolve as habilidades de auto-desenvolvimento dos atores sociais, dentre os quais ele próprio, como agente da elaboração teórica. $\mathbf{A}$ acumulação de conhecimento da ciência social é obtida através da estruturação da teoria substantiva que possa auxiliar na interpretação dos fenômenos singulares, e do refinamento metodológico em aplicações práticas, gerando aperfeiçoamentos metodológicos. 
As três potencialidades descritas acima leva-nos a reafirmar duas importantes idéias: (1) a demanda por Q\&P abre espaço para a utilização do conhecimento especializado da engenharia de produção; e (2) os pressupostos básicos de Q\&P abrem horizonte para a formulação de uma nova base teórica e prática da engenharia de produção, em interrelação estreita com as necessidades do setor produtivo. Isso, no entanto, não pode se concretizar sem que a Q\&P se beneficie da experiência já acumulada na EP, de forma a superar suas limitações atuais.

\section{Limitações da Q\&P}

A primeira limitação do tema $Q \& P$, operacionalizado a nível nacional pelo Programa Brasileiro de Qualidade e Produtividade, (PBQP) e a nível organizacional pelos programas de Q\&P, refere-se aos resultados obtidos. Sabe-se que a implementação dos programas resultou em significativos incrementos de qualidade e produtividade, e, consequentemente, maior competitividade e maior possibilidade de sobrevivência das organizações. Entretanto, conhece-se também, o lado negativo, a geração de excedentes de mão-deobra, inclusive em função da diminuição dos níveis hierárquicos. Muitas organizações, em vez de realocar o seu pessoal, têm dispensado pessoas, e de forma crescente com a difusão dos programas de Q\&P.

A segunda limitação está ligada diretamente à comunidade da Engenharia de Produção. Conforme já colocado anteriormente, verificou-se que nos diversos ENEGEPs já realizados, os comitês técnicos divergiram no estabelecimento dos critérios quanto ao agrupamento dos trabalhos do sub-grupo Q\&P. Acresce-se a isso que alguns pesquisadores têm se mantido longe do Q\&P por causa do caráter demagógico do tema, como também da simplicidade das técnicas até então utilizadas. Para estes o Q\&P é a moda que em breve passará, pois é praticado pelos menos informados, sem profundidade acadêmica e nenhum rigor cientifico. Outros, se apoiando numa errônea concepção de trabalho acadêmico, se distanciam voluntariamente dos setores produtivos, não sabendo ou não importando com o significado de uma pesquisa voltada para a realidade; permanecem no refinamento de técnicas e pesquisas de gabinete, presos à avaliação puramente quantitativa das publicações, imposta pelas universidades e orgãos de fomento. Entretanto, parece-nos que essa postura não favorece o desenvolvimento do corpo-teórico e nem contribui para a prática da Engenharia de Produção no Brasil. Esse distanciamento parece-nos não ser de todo injustificado pois, como veremos a seguir, a QT tende a ser, tanto na prática como na teoria, reducionista, simplificando a complexidade da realidade contraditória da produção. Apoiando-se sobre uma noção puramente "técnica" da produção, reduzida às relações imediatas entre processos e pessoaas, a QT retém somente aquelas relações funcionais necessárias para se obter certos resultados. Por isso, acomoda-se sem dificuldades no interior da divisão social do trabalho, preservando a hierarquia, ao mesmo tempo (et pour cause) que abre canais de expressão direta para os trabalhadores. Todavia, isso tudo não impede que problemas e necessidades reais tenham sido revelados, pelos quais a $\mathrm{EP}$, como um todo, deve também se interessar.

A terceira limitação é a pouca possibilidade de sustentação do tema Q\&P por um periodo longo, com seu atual corpo conceitualteórico. Reconhecidamente a Q\&P, notadamente a Gestão da Qualidade Total, é o tema da "moda". Mas, em termos práticos, resumese ela a mais um modismo (como a "Reenge- 
nharia") ou traz consigo conhecimentos práticos duradouros? Sua ampla aceitação reflete um consenso profundo entre as diversas classes sociais ou, ao contrário, por que ela se presta bem a determinados interesses das classes hegemônicas? Não estamos diante de formas mais refinadas de manipulação? Para responder a estas indagações, parece-nos necessário abordá-las por outros ângulos que aquele que nos apresenta a própria $\mathrm{QT}$, isto é, olhá-la de "fora", a partir da experiência de outras disciplinas e da própria tradição da EP. Em primeiro lugar, a aparência de modismo, acentuada pela rapidez de sua penetração, não pode esconder alguns efeitos práticos visiveis. Em poucos anos conseguiu-se divulgar mais a EP do que em toda a sua existência no Brasil. Que isto se faça através de princípios teóricos relativamente simples (e às vezes simplistas) ou por práticas já bastante tradicionais. (como a racionalização taylorista e a padronização) É não apenas uma consequência da falta de profundidade teórica da QT, mas indica sobretudo a pouca profundidade de penetração da EP na organização e gestão industrial. A limitada profundidade dos principios e técnicas da QT mais conhecidas, que tanto encantaram o mundo industrial, dos diretores aos operários, passando mesmo por alguns sindicalistas, revela-nos quão pouco o ensino da EP conseguiu se traduzir em prática efetiva. Como todo movimento de massa, e foi isso que se deu, não era evidentemente possivel trazer à baila o tema de Q\&P e conduzí-lo nos moldes da sofisticação da pesquisa, do debate e mesmo do ensino acadêmico. Tratava-se, antes, de obter um efeito mobilizador de todo um país, e, aparentemente, isto foi alcançado, ou está prestes a sê-lo. No entanto, o aspecto perverso é que este movimento, embora constituindo um efeito notável em tão curto tempo, reconhecido e admirado pelos próprios "mestres" japoneses, não tem as forças necessárias para se auto-susten- tar só com o atual corpo de conhecimento.

A quarta limitação é a simplificação da realidade da produção. Sabidamente a QT centra sua ação na mudança cultural e na educação. Porém, esse é apenas um primeiro passo de qualquer transformação efetiva da realidade. Se é verdade que os homens agem guiados pela sua consciência, eles agem para torná-la realidade efetiva, transformando as circunstâncias de sua vida. Por outro lado, são as circunstâncias, como vimos, que geram, através de problemas colocados aos homens, certas formas de consciência para enfrentálos. Cumprida a fase de sensibilização e de conscientização, trata-se agora de se colocar à prova da realidade, isto é, de realizar o programa proposto. E aqui, nos parece, reside o grande defeito da QT; para ser aceita de forma ampla, simplificou a realidade da produção, eliminando, por exemplo, as contradições e conflitos existentes, e a si mesma, enquanto teoria que pretende refletir como as coisas são, e não simplesmente como elas devem ser. Não importando aqui as diferentes concepções sobre o que é a realidade da produção, o fato é que chegou o momento da QT mostrar sua real eficácia e, para tanto, ela deve necessariamente se desenvolver e se enriquecer, aprendendo com a sua própria prática e com as criticas que the são feitas, caso ela pretenda ser algo mais que um mero modismo. Para tanto, problemas teóricos e práticos deverão ser agora seriamente considerados. A falta de meios teóricos e práticos realmente efetivos diante das questões reais que transcendem a conscientização obtida pela QT, aparece claramente quando confrontada com a "Reengenharia". Este modismo de caráter cínico é irrealista, por exemplo, quando propõe mudanças "radicais", como se algo pudesse começar do zero; porém, ao assumir claramente seu descompromisso com questões sociais, como o desemprego, acaba oferecendo al- 
guns instrumentos práticos efetivos, tais como o redesenho dos processos e o uso da informática. A boa consciência, mas ainda pouco efetiva, da QT, se contrapõe à total falta de consciência social da Reengenharia. $O$ que então pode ser feito para que a Q\&P e a EP cumpram, não somente uma função técnica, mas também um papel social? Antes de tudo, nos parece ser necessário que os divulgadores e praticantes da QT começem a refletir sobre os resultados ambíguos, ao invés de se limitar a justificá-los através de racionalizações puramente comportamentais, psicológicas, educacionais ou éticas. Se é verdade que a QT implica e requer a educação para elevar a qualidade e a produtividade, é igualmente evidente que ela não pode se reduzir apenas a esse aspecto.

\section{Ações Propostas}

As ações propostas a seguir são derivadas das limitações e potencialidades apontadas na seção anterior. Estas estão divididas em propostas de caráter teórico e prático para a comunidade de pesquisadores da Engenharia de Produção, associações afins e orgãos de fomento. Comecemos pelas questões mais gerais.

\section{Questões Teóricas Gerais}

Vimos que o efeito mobilizador da QT se legitima, em grande parte, pelos pressupostos de que: (1) o "sucesso" japonês pode se repetir no Brasil; (2) a QT é a chave que explica o sucesso japonês; (3) a QT pode salvar o Brasil. Ora, o raciocínio é lógicamente fundamentado, mas com pouca base real. Sem querer negar o papel da dimensão da consciência e mesmo da gestão e organização, é necessário reconhecer que temos ai apenas uma das causas que contribuíram para o sucesso econômico japonês, e sabemos que as causas são múltiplas e se articulam de forma extremamente complexa. No caso do Japão, um grande número de fatores têm sido apontados como causa do seu sucesso, dos valores religiosos e culturais à determinados eventos históricos, passando pelas instituições sociais, estrutura industrial, política estatal, organização do trabalho e da produção e, até mesmo, a psicologia individual. Todo esse processo está ainda obscuro e deveria ser melhor esclarecido por duas razões: (1) descobrir o papel efetivo (e possivel) da QT no interior do complexo de determinações que ordenam a sociedade japonesa, e propiciaram o seu sucesso econômico; (2) fazer com que este "sucesso econômico" se transforme em "sucesso social".

Resolver as difíceis questões subjacentes ao processo de desenvolvimento econômico e social de um país como o Brasil, e sua relação com as formas de organizar a produção, em suma, descobrir como o "micro" e o "macro" se relacionam, requer a compreensão, de um lado, da natureza da sociedade japonesa e de sua evolução no interior do sistema capitalista mundial e, por outro lado, da própria natureza do capitalismo brasileiro.

No interior dessas questões gerais, que aparentemente nada interessam à EP, se colocam problemas especificos, teóricos e práti$\cos$, que a QT está convocada a responder. $\mathrm{O}$ primeiro deles diz respeito à própria noção central de "qualidade". Aqui muitas questões ainda estão abertas ou pouco exploradas. A qualidade de um produto ou serviço se concretiza no seu valor de uso para o consumidor que, todavia, está em contradição com valores e interesses econômicos. Como então a QT pode conciliá-los? Esta não é uma questão meramente teórica, mas de profundas reper- 
cussões práticas, micro e macroeconômicas. Como o Brasil pode distribuir e atribuir diferentes patamares de qualidade para atender, tanto ao mercado externo, quanto às necessidades de todos os brasileiros? No âmbito das técnicas e procedimentos da EP, como traduzir as reais necessidades, uma vez identificadas, dos consumidores em requisitos de projeto e parâmetros de produção? Dado o caráter em parte inconsciente das necessidades, seja pela manipulação dos desejos, seja sobre o plano psicológico da prática cotidiana, como explicitar e identificar as necessidades reais? Aparecem aqui, em dois planos - o psicológico e o social- lacunas que as técnicas de desenvolvimento de produtos da QT (QFD) devem procurar resolver.

Em segundo lugar, o conhecimento dos processos sociais ocorridos no Japão propiciará condições para um melhor discernimento sobre o que é meramente ideológico e o que é praticamente eficaz em termos de reorganização da produção. Também aqui o QFD está implicado, pois não bastam bons princípios de concep̧̧ão de produtos, mas uma estrutura organizacional e produtiva que permita concretizá-los. Que formas organizacionais permitem efetivar os princípios de qualidade? Como conciliar e obter o acordo de diferentes partes da empresa em torno de um valor que, às vezes, está em contradição com outros valores e interesses? Que transformações organizacionais e do ambiente são necessários? Como elas obtêm tais efeitos, através da coerção ou do livre consentimento das partes? Que relações e conflitos se estabelecem com as novas formas de relacionamento com os fornecedores?

E aqui chegamos a um terceiro aspecto: a implicação dos trabalhadores na produção voltada para a QT. Caracterizamos tanto Q\&P quanto a EP de forma ampla: à qualidade do produto conjuga-se a necessidade de uma maior qualidade de vida no trabalho. Em que medida e como se obtem o envolvimento dos trabalhadores? Como mantê-lo quando se vê que os programas de QT são sempre acompanhados de desemprego? Os conflitos de interesses estão resolvidos ou apenas adormecidos? Como o envolvimento foi obtido no Japão? Através de contrapartidas e vantagens no emprego ou por razões culturais e psicológicas? Pela coerção, implícita ou explícita, ou pelo convencimento? Finalmente, por que uma produção, que se funde cada vez mais na ciência e na tecnologia, necessitaria da participação dos produtores diretos, cada vez em menor número? Que vantagens, ideológicas ou materiais, esta implicação traz para a empresa? $O$ que isto significa em termos de reorganização do trabalho e de qualificação efetiva dos trabalhadores?

\section{Propostas Específicas}

Um primeiro conjunto de ações concernem a comunidade da EP nas pessoas de seus pesquisadores. É necessário tratar do tema Q\&P em relação com as suas pesquisas particulares. Alguns escritos mais recentes têm abordado o desafio que o tema Q\&P coloca ao tradicional corpo conceitual-teórico de gestão (Grant, Shani \& Krishnan, 1994). Empresas como Motorola e Milliken têm aberto seus programas de treinamento aos professores universitários, para que estes complementem sua formação, pois parece que os profissionais do setor produtivo possuem um conhecimento mais aprofundado do tema Q\&P do que os que estão nas universidades (Grant, Shani \& Krishnan, 1994). Por outro lado, temse verificado que grande parte das pesquisas desenvolvidas têm tido pouco impacto sobre setores produtivos, pois o mero refinamento de métodos e técnicas no ostracismo dos ga- 
binetes, sem conhecer de forma mais aprofundada a realidade pesquisada, levam a resultados quase sempre estéreis.

A complexidade das questões relativas à $\mathrm{Q} \& \mathrm{P}$, anteriormente mencionadas, sugere que sejam desenvolvidas estratégias igualmente abrangentes para se dar conta dos vários aspectos envolvidos nas tendências atuais do mundo da produção. Pensamos que estudos comparativos entre diferentes realidades nacionais e setores da produção, poderiam ser uma forma adequada para desvendar algumas questões ainda abertas, o que exigiria a constituição de equipes multidisciplinares e interinstitucionais. Quanto ao incentivo de pesquisas conjuntas, têm-se observado que os trabalhos apresentados nos ENEGEPs possuem, ainda, um caráter eminentemente acadêmico, mesmo quando contêm alguma característica prática. Acreditamos que somente uma maior ênfase nos estudos empiricos mais exaustivos, (obviamente sem se restringir à simples coleta de informações ou à mera casuistica dos exemplos) seria capaz de dar relevância aos trabalhos de pesquisa do ponto de vista das necessidades da produção (no seu sentido amplo).

Em termos de ensino de EP, a emergência da área de Q\&P tem revelado a insuficiência da formação tecnicamente orientada, isto é, que enfatiza a especialização em áreas restritas em detrimento de uma concepção ampla e integrada dos processos produtivos, o que nada mais é que o reflexo das mudanças das formas de organização da produção. Por outro lado, o caráter ainda relativamente indefinido, mutável e complexo da reorganização em curso, colocam problemas novos que requerem a capacidade inventiva dos profissionais de engenharia, não tanto para aplicar técnicas que thes foram ensinadas nas escolas, mas para definir o escopo dos problemas reais.
Assim, nos parece ser necessário acentuar a aprendizagem ativa, através da participação dos alunos de graduação em pesquisas de campo, (iniciação científica, por exemplo) e de trabalhos aplicados (estágios e trabalhos de conclusão de curso) dentro das empresas.

Quanto a nossos encontros, não há dúvida que os ENEGEPs, no decorrer dos anos, têm tido um sucesso crescente, se constituindo no mais importante acontecimento anual da comunidade. Entretanto, face à dinamicidade dos acontecimentos, observa-se que há uma necessidade de travar discussões mais profundas, em um forum mais apropriado, sobre o perfil da Engeneharia de Produção do Brasil, e como esta área do conhecimento pode ser mais relevante à sociedade brasileira. Espera-se que este trabalho suscite reflexões e auxilie na confecção do documento "Avaliação e Perspectivas da Engenharia de Produção", e também subsidie a elaboração de um plano de ações mais abrangente para direcionar os trabalhos dessa área.

Duas propostas de ação aos orgãos de fomento, seriam incentivar fortemente a pesquisa conjunta entre o setor produtivo e universidades, e apoiar estágios de pesquisadores em setores produtivos. Nos últimos dez anos tem-se visto um incentivo muito grande, para que os professores da Engenharia de Produção espalhados por todo o país pudessem titular-se, nos niveis de mestrado e doutorado. Entrentanto, uma boa parte destes seguiram a carreira acadêmica, a partir da graduação, sem ter tido a oportunidade de conhecer de perto a dinâmica dos processos produtivos. Esta possivel deficiência de formação somente pode ser superada com um retorno à pesquisa e reflexão sobre a realidade da produção e, a partir desta mesma realidade, sobretudo num momento de transformações tão importantes, que não se deixam enquadrar 
nos conceitos e princípios usuais. É preciso assinalar, no entanto, que as empresas nacionais, por seu lado, ainda colocam restrições significativas a essa interação, somente abrindo suas portas na medida de seus interesses imediatos.

\section{Conclusões}

É inquestionável, portanto, que a QT tenha aberto um importante espaço para a discussão sobre as novas formas de organização da produção, de concepção de produtos e gestão da força de trabalho, no qual a EP pode e deve intervir, não porque ela precise aproveitar a "onda", mas porque a QT precisa desenvolver um conteúdo substancial, que seus princípios teóricos e o instrumental, ainda précario, não são capazes de fornecer. Nesta interação, ambas podem sair beneficiadas: a QT ganhando em eficácia prática, e a EP ganhando o espaço da produção.

A tarefa que se coloca diante de todos nós requer, no entanto, que abandonemos a retórica dos bons princípios e o apriorismo dos métodos, em benefício do conhecimento concreto da realidade da produção, e de suas necessidades reais. $O$ primeiro passo é não restringir somente as generalidades da QT que se aplicam indistintamente na indústria, na educação ou na saúde, mas aprofundar-se nas especificidades. Quando retornarmos às coisas elas mesmas, veremos que estas realidades são de naturezas diversas, e a solução de seus problemas requerem abordaǵens e instrumentos específicos. No que diz respeito à produção material, os conhecimentos acumulados pela EP e por outras disciplinas sobre suas lógicas contraditórias podem dar um fundamento concreto para auxiliar, de forma critica e cooperativa, a efetivação dos principios gerais da produção voltada para a quali- dade - do trabalho e dos valores de uso.

Este trabalho possui um tom voluntariamente polêmico para que possa suscitar um processo de discussão sobre o tema Q\&P e sobre a própria EP, ou melhor, sobre o que é fazer EP no Brasil. Identifica-se várias deficiências do trabalho, tais como: análise limitada à evolução do conceito do controle da qualidade, e a limitação dos dados disponiveis. Entretanto, esperamos que o seu conteưdo seja relevante o suficiente para levantar um processo de reflexão sobre o tema. Os autores se consideram gratificados, se esse objetivo for alcançado.

\section{Referências Bibliográficas}

Anais do IX ENEGEP (1989) Encontro Nacional de Engenharia de Produção. ABEPRO. Porto Alegre.

Anais do VIII ENEGEP (1988) Encontro Nacional de Engenharia de Producão. ABEPRO. São Carlos.

Anais do X ENEGEP (1990) Encontro Nacional de Engenharia de Producão. ABEPRO. Belo Horizonte.

Anais do XIII ENEGEP (1993) Encontro Nacional de Engenharia de Producão e I Conresso Latino Americano de Engenharia Industrial. ABEPRO. Florianópolis.

AKAO, Y. (1972) New Product Development and Quality Assurance: System of Quality Function Deployment.Standardization, and Quality Control. Vol 25, No. 4, 9-14, JSA. 
AKAO, Y. OFUJI, T. \& ONO, M. (1990) Hinshitsu Tenkai Katsuyo Manuaru. 3 Volumes. JUSE, (em japonês).

BURRELL, G \& MOREAN, G. (1979)Sociological Paradigms and Organisational Analysis. Heinemann. UK.

CORIAT, B.Penser à l'envers. Paris, Christian Bourgeois, 1991.

DRUMOND, F. B. \& CHENG, L. C. (1994) Papel dos Métodos Estatísticos no Desdobramento da Função Qualidade.110 SINAPE - Simpósio Nacional de Probabilidade e Estatística. BH. MG.

Fundação Christiano Ottoni (1992) Seminário de Desdobramento do TQC. $\mathrm{BH}$, MG.

Fundação Christiano Ottoni (1993) Casos Reais de Implantação de TQC. 2 Volumes. BH. MG.

GRANT, R. M., SHANI, R. \& KRISHNAN, R. (1994) TQM's Challenge to Management Theory and Practice.Sloan Management Review. Winter 1994. Volume 35, Number 2, Pages 25-35.

GM do Brasil (1991) Manual de Referência: Sistema de Determinação das Caracteristicas Principais. GM1805, GMB.

HIRATA, H. (org) Sobre o modelo japonês.

ISHIKAWA, K. (1984)Quality and Standardization: Program for Economic Success. Quality Progress. Vol 17, No. $01,16-20$
JUSE (1991) Organization \& Activities. Union of Japanese Scientists and Engineers. Japan.

JUSEProblem Solving Research Group (1991) TOC Solutions: The 14 Step Process. Productivity Press. Cambridge. MA.

LUSTOSA, L \& Iida, I (1989) Programa Nacional de Engenharia de Produção. CNPq.

LIMA, F.P.A. "<<Qualidade Total $>>$ e reorganização produtiva: uma avaliação critica". Anais do XIII ENEGEP, Florianópolis, 1993.

MORGAN, G. (Ed) (1983) Beyond Method. Sage Publications, London.

PORTER, M. E. (1989) Vantagem Competitiva. Editora Campus. RJ.

PORTER, M.E. (1993)A Vantagem Competitiva das Nacões. Editora Campus. RJ.

Programa Brasileiro da Qualidade e Produtividade (1991) Ministério da Economia, Fazenda e Planejamento, Ministério da Justiça, e Secretaria de Ciência e Tecnologia. Brasília.

THUROW, L. (1992) Head to Head. William Morrow and Company Inc.. NY.

WOMACK, J.P.; JONES, D.T. \& ROSS, D $\underline{A}$ máquina que mudou o mundo. Rio de Janeiro, Campus, 1992 (3a ed.) 